\title{
K-Design: the New Design Vision for the New Korean Government
}

K-Design is a new vision declared by Korea Institute of Design Promotion (KIDP) in December, 2012, and now is a keyword of Korean design policy. K-Design is not a fully developed concept, but a vision which aims to develop the unique Korean design identity that can appeal to the world. This rather a vague term is often found in design related government projects. In those contexts, K-Design is perceived as a method supporting the idea of "creative economy", which is the core economic principle that has been proposed by the new regime. This situation coincides with the paradigm that penetrates the history of Korean design policy: design is a tool for improving economic value of products, yet shows some difference. Through investigations on the definition and the usage of the term K-Design, this paper aims to reveal the current Korean government's perception on design.

keywords K-Design, design policy, design promotion, South Korea, government

\section{Introduction}

Ever since the Korea Institute of Design Promotion (KIDP) declared a new vision called "K-Design" in December 11th, 2012, it has become a keyword of Korean government's design policy. As a public organization affiliated to the Ministry of Trade, Industry and Energy (MOTIE), KIDP has long been in charge of design policy at government level since 1970s. Although there were not a few agendas and policy proposals regarding design throughout the Korean history, this kind of vision announcement has never appeared before. This can be interpreted that design is now perceived as an important administrative issue in the Korean government. Considering the fact that the vision was published at the precise moment of regime change, it would not be too much to say that K-Design represents the role of design in the new Park Geun-hye regime?.

From the early 6os, the Korean government has treated design as a powerful tool for economic development, which led to centralized design promotion policy. Due to the growing interest on design, this point of view has gone through a lot of changes; on the other hand, some of the principles still remain the same. Even K-Design, the newest political statement on design, is no exception. In this context, K-Design can be a good example to help us understand the current state of design policy in Korea. Through investigation on the concept and usages of K-Design, this paper aims to reveal how Korean government perceives the role of Design today. 


\section{The Definition of K-Design}

As mentioned above, K-Design is a new concept made by government officials; hence, it is inevitable to check the definition given by the creators. According to a book published by KIDP, K-Design refers to a good design that represents the Korean design identity, a.k.a. "Koreanness", in a harmonious manner, regardless of the origin of design. Then what is the Korean design identity? The book says that the Korean design identity consists of aesthetic and philosophical DNAs of Korea, and features of Korean design that global citizens are aware of. In addition, KIDP asserts that K-Design is never a concept that is just limited to formalistic imitation or reinterpretation of traditions, but it means that it is necessary to learn Korean traditions and to combine them with current trends in order to make Korea's own design with unique personality; also, it is encouraged to pursue the universality in consideration of consumers overseas. (KIDP 2013: 12)

Despite the eloquent explanation, all of these sounds pretty ambiguous. That is because many of the words used to explain K-Design are not concretely defined. For example, the presented definition of K-Design requires the understanding of Korean design identity, which cannot be learned unless one already has background knowledge on aesthetic and philosophical DNAs of Korea. In this way, the words which are supposed to explain and support the idea of K-Design make problem all the more complicated. Even though K-Design shares "K-" with K-Pop ${ }^{2}$ and K-Wave ${ }^{3}$, it is totally different from them. K-Pop and $\mathrm{K}$-Wave are naturally coined after huge sensations made by Korean pop culture, while K-Design is artificially made without any remarkable influence. The creators of the term named it after those successful $\mathrm{K}$ words, hoping that K-Design will be renowned in the world just like K-Pop someday in the future. Therefore, the given definition of K-Design is not a description of the concept, but rather a pursuit of value. This is probably why KIDP introduced K-Design as a "vision."

In short, the term K-Design implicates the strong desire for the development of original Korean design which represents the "Korean design identity" and appeals to the world.

\section{The usage of the term K-Design in actual design related policies}

Since the definition given by the creators was not enough to clarify the meaning, it is helpful to observe what kind of projects and events are actually performed under the name of K-Design. The following are the most noticeable examples which directly implemented the term and the concept of K-Design.

\subsection{K-Design DNA Project}

As an effort to find the Korean design identity, KIDP launched a project called "K-Design DNA". It is basically a research project which aims to discover the origin of Korean Design. Experts of architecture, furniture, china, fashion, philosophy, fine arts and industrial design have chosen the 141 designs representing Korea, and deduced the key characteristics of K-Design DNA for each area. For instance, many of the selected examples share the emphasis on human-scale and harmony with nature; from this, the experts abstracted "design in unity with the nature" as a design DNA of Korean architecture. Although it

\footnotetext{
${ }^{2}$ Korean popular music.

${ }^{3}$ Acronym for Korean Wave, which refers to the increase in the popularity of South Korean culture since the late 1990 s.
} 
is questionable whether the true Korean design identity can be established in this way, KIDP seems to be satisfied with the result and plan to spread it to public, especially to both professional and amateur designers.

\subsection{Design Korea 2013: K-Design, New Changes Creating the Future}

Launched in 2003, "Design Korea" is an annual design exposition, whose purpose is to understand the current address of the domestic and international design industry and to propose its future direction. The theme for Design Korea 2013 is "K-Design: New Changes Creating the Future." As an event sponsored by MOTIE, Design Korea has been used as an occasion to promote the design policies of the government. Without doubt, Design Korea 2013 also represents the Park government's perspective on design, which is clearly seen in the outline of the event written on the official homepage. It says that we are currently in the midst of a new change, witnessing the world change from the 3rd wave or the "information era" to the 4 th wave, the so-called "creative era."

According to the homepage, if labor, technology and information had been the key elements that led the economic growth of countries and societies, elements based on creativity such as design, contents, software and engineering are expected to become the new growth engine in the "creative era." It also argues that amongst such elements, experts agree that "design" most definitely shall become the next growth engine that will lead the new era of change. (Design Korea Homepage 2013) The slogan below concisely summarizes not only the main theme of the event but also the basic principle of design policy in current government: Design is creativity. Design is economy. Design is the force that creates the future.

\subsection{K-Design Contest}

K-Design Contest is an audition for Korean designers. Just like other popular audition programs, the whole process of the audition is filmed and broadcasted on television, and the prize money is huge. The format is also very alike: One mission is given to the challengers every week; judges evaluate the result of the mission and select the best and the worst; the worst has to leave the audition, while others stay and continue the journey for the prize. Only difference between K-Design Contest and other auditions is that the former was led by official government organizations, KIDP and MOTIE, which is quite unusual for an audition on TV. The aims of the audition written in the participant recruit notice on the KIDP homepage shows this difference all the more clearly:

- To create economic value of design in accord with the creative economy policy of government.

- To select design products which represents the design identity of Korea (Koreanness), and promote them at home and abroad.

- To enlarge the base and improve the status of Korean design in the world through K-Design. (KIDP homepage 2013)

As can be seen from above, the language used to define K-Design in the book published by KIDP also appears in the announcement. This shows that K-Design Contest is not a simple audition which searches for a star designer of the next generation; the ultimate goal of this program is to promote the new vision of K-Design in and out of the country.

\section{The role of Design in Korean Government: In a Historical Perspective}

With a close observation on the definition and the usages conducted in the former two chapters, we can extract the two major goals of K-Design: 1) to pursue the unique Korean identity (as in 2. 1. and 2. 3.), and 2) to generate the economic value which coincides with the creative economy policy (as in 2. 2. and 2. 3.). Considering that K-Design is a vision recently made by a government affiliated institute and it is usually discovered in projects and policies at government level, it can be assumed that these two goals represent what current government expects from design. 
Even though K-Design is a relatively new term which was declared at the beginning of current regime, an attitude of perceiving design as a tool for improving economic value of products, underlying the second goal of K-Design vision, is rather old. In 1960 s to 1970 , the biggest concern of the Korean government was focused on the expansion of export in order to stabilize the economy from the trauma of the war. In these years, the government started to recognize packaging and design as an important measure for improving the value of exporting products. In 1970, Korea Design Packaging Center, which later became KIDP, was established with the support of the Ministry of Commerce. (Kim 2008: 42) The main purpose of this institution was to develop better packaging design skills that can support the sales of Korean products in the world market. (KIDP 2010: 26)

In fact, the idea of design as a tool for creating economic value and enhancing economic competitiveness appears in many other countries beside Korea. (Woodham 2010: 42) However, the situation of Korea in 1970 s was different from western countries who already had stabilized GDP and played a leading role in world economy. In order to step up from the status of developing country and to stand shoulder to shoulder with advanced countries in a short period, the Korean government did not hesitate to sacrifice the originality of design. What was expected for design was to make a good result that can lead to sales; as long as it sells well, the quality and creativity of design did not matter much. A design critique has warned that this highly economic-centered policy are leading designed products to be mere imitations which lack regional and national contexts. (Kim 2000)

When the goal of economic development had approached a success in 1990s, designers along with other professions started to think about the values and traditions it sacrificed and a search for the "Koreanness" were triggered by some designers and academics. Still, the government's policy regarding design was focused on creating additional economic value rather than defining Korean design identity. It was not until the declaration of the K-Design vision in 2012 that the government officially initiated the development of original Korean design which represents the "Korean design identity."

Unlike other countries such as Germany or Japan that actively utilized design as a method to show the distinctive identity of their products in world market, Korean government had little interest in supporting designers to research and develop Korea's own design identity, which is likely to take more time and cost than improvising whenever the market demands. Therefore, the pursuit of Korean design identity contained in the K-Design vision is important because it indicates the change of attitude toward design within the Korean government; design can also be a symbol which represents culture and legacy of a nation, not a mere tool that serves economic ends. However, as it can be seen in the example of K-Design DNA project, the government is still captured in the same top-down approach as they used in the 1970 s when making design related policies. Important issues like the design identity of Korea, or "Koreanness" cannot be excavated from the government level and be handed down to the public; in order to fully realize the vision of K-Design, a new decision making system that can reflect this change should be followed.

\section{Conclusion}

So far, the concept and examples of K-Design has been reviewed and a brief history of design policy in Korea has been introduced in the purpose of revealing the role of design in Korean government. Through this process, it is demonstrated that K-Design, the new vision for design which is developed by KIDP, shares the old Korean paradigm of design as a promotion tool for economic growth yet initiates the search for the design identity of 
Korea that has been neglected in the design policy for a long time. Although the intention of pursuing the unique Korean identity and generating the creative economic value is encouraging, it seems that the way of promoting the new vision still depends on the centralized approach from the intensive development phase of Korea in 1970s. Developing administrative program that is more coherent to achieve the purpose of the K-Design vision still remains as an assignment of the government.

\section{References}

Book with one author

Korea Institute of Design Promotion. (2010) Korea Institute of Design Promotion 40 years, Gyeongi: Korea Institute of Design Promotion.

Korea Institute of Design Promotion. (2013) Why K-Design?, Gyeongi: Korea Institute of Design Promotion.

Journal Article

Kim, Min-soo (2000) 'Korean Art Democracy in Void: Design Politics without Politics', Design Culture Criticism, Vol. 2., Seoul: Ahn Graphics.

Woodham, Jonathan M. (2010) 'Formulating National Design Policies in the United States: Recycling the "Emperor's New Clothes"?, Design Issues, Vol. 26, No. 2. Boston: MIT Press.

Thesis

Kim, Jong-kyun (2008) 'A research on the development direction of the Korea design promotion system', Doctor of Design Thesis, Seoul National University.

World Wide Web Page

Design Korea, http://www.designkorea.or.kr/ [10 January 2014]

Korea Institute of Design Promotion, http://www.kidp.or.kr/ [10 January 2014]

K-Design DNA, http://kddna.designdb.com/ [10 January 2014]

Ministry of Trade, Industry and Energy, http://www.motie.go.kr/ [10 January 2014] 